\title{
Ruptured ectopic pregnancy in rudimentary horn
}

\section{Nivedita A. Goverdhan*, Alka Patankar}

Department of Obstetrics \& Gynaecology, Indira Gandhi Government Medical College, Nagpur, Maharashtra, India

Received: 03 February 2016

Accepted: 01 March 2016

\author{
*Correspondence: \\ Dr. Nivedita A. Goverdhan, \\ E-mail: niveditagoverdhan@gmail.com
}

Copyright: $($ ) the author(s), publisher and licensee Medip Academy. This is an open-access article distributed under the terms of the Creative Commons Attribution Non-Commercial License, which permits unrestricted non-commercial use, distribution, and reproduction in any medium, provided the original work is properly cited.

\begin{abstract}
A unicornuate uterus with a rudimentary horn is a rare mullerian abnormality which may cause many gynaecological and obstetrical complications like infertility, endometriosis, hematometra, abortions, and preterm deliveries; and is usually associated with urinary tract anomalies. Pregnancy in a non-communicating rudimentary horn is very difficult to diagnose before it ruptures, leading to life -threatening intraperitoneal hemorrhage, which usually presents in the second or third trimester. A 23 year old G2P1L1 in lactational amenorrhea was admitted to the labour room with haemorrhagic shock. Provisionally diagnosed as ruptured ectopic pregnancy, patient was taken for laparotomy after resuscitation. Intraoperative findings were: haemoperitoneum of 3 liters, unicornuate uterus with a ruptured left rudimentary non-communicating horn containing products of conception, and macroscopically normal fallopian tubes and ovaries. The left adnexa were attached to the rudimentary horn. Excision of the rudimentary horn was done. The fetus, weighing about 250 grams, was recovered en-sac from the peritoneal cavity. There is a need for an increased awareness of rudimentary horn pregnancy especially in developing countries where the possibility of detection before pregnancy or before the rupture is unlikely, and precious time is lost in shifting these women to the referral hospital.
\end{abstract}

Keywords: Ruptured ectopic, Rudimentary horn pregnancy, Unicornuate uterus

\section{INTRODUCTION}

Ectopic pregnancy refers to the implantation of a fertilized egg in a location outside the uterine cavity, including the fallopian tubes, cervix, ovary, cornual region of the uterus, and abdominal cavity. The abnormally implanted fetus grows and draws its blood supply from the abnormal implantation site. As the fetus enlarges, it creates the potential for organ rupture because only the uterine cavity is designed to expand and accommodate fetal development. ${ }^{1}$ A unicornuate uterus with a rudimentary horn is a rare mullerian abnormality which may cause many gynaecological and obstetrical complications like infertility, endometriosis, hematometra, abortions, and preterm deliveries; and is usually associated with urinary tract anomalies. Pregnancy in a non-communicating rudimentary horn is very difficult to diagnose before it ruptures, leading to life -threatening intraperitoneal hemorrhage, which usually presents in the second or third trimester.

\section{CASE REPORT}

A 23 year old G2P1L1 attended the medicine OPD, for complaints of giddiness and severe abdominal pain of about 8 hours duration. In view of lactational amenorrhea and profound shock, she was directly referred to the labour room. There was no history of vaginal bleeding. On admission in the labour room, the patient was found to be in haemorrhagic shock; she was very pale, anxious, with blood pressure of 90/60 mm Hg, weak, low volume pulse of 120/minute. Immediate resuscitation was started with IV fluids. IV access was secured with wide bore canulas, and samples were drawn for investigations, blood grouping and cross matching. History was elicited after the patient was relatively stable. She had a previous 
uneventful vaginal delivery 9 months back. Abdominal examination revealed diffuse tenderness, guarding and dullness on percussion. On pelvic examination, there was fullness and tenderness in the fornices. Cervical motion tenderness was noted but bimanual examination was limited by pain. A urine pregnancy test was done, which was weakly positive. The provisional diagnosis was a ruptured ectopic pregnancy. The patient was immediately shifted for an emergency laparotomy under general anesthesia. Pre-operative workup showed a hemoglobin level of $6 \mathrm{gm}$. Operative findings were: hemoperitoneum of 3 liters, a unicornuate uterus with a ruptured left rudimentary non-communicating horn containing products of conception, and macroscopically normal fallopian tubes and ovaries. The left adnexa were attached to the functioning horn. Excision of the rudimentary horn was done. The fetus, weighing about 250 grams, was recovered en-sac from the peritoneal cavity. The patient received three units of packed red blood cells. Uneventful post-operative course followed and the patient was discharged seven days later.

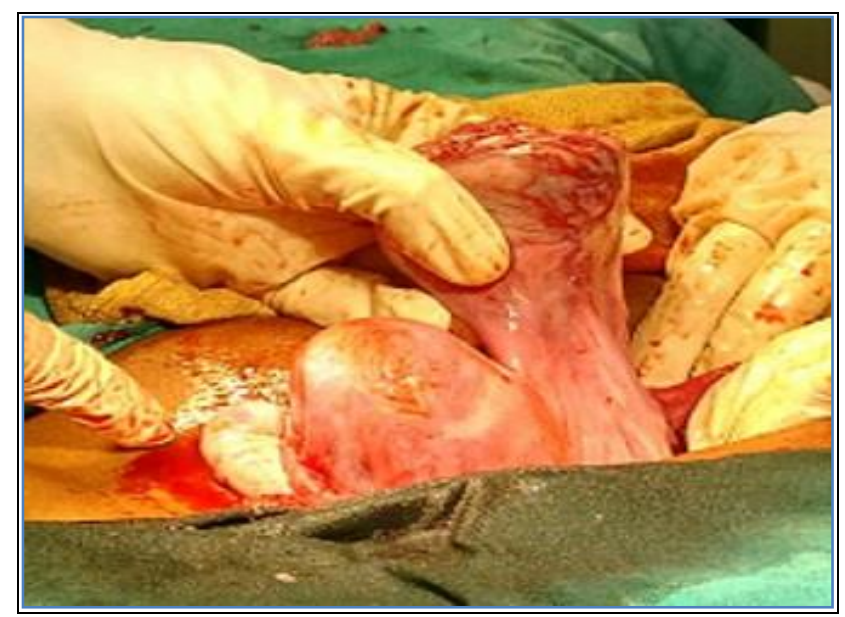

Figure 1: Left ruptured rudimentary horn.

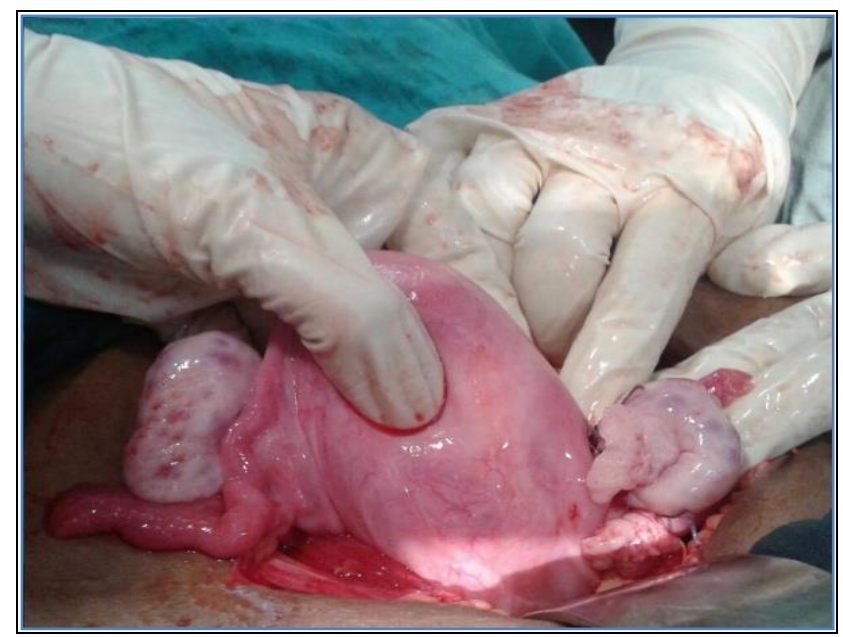

Figure 2: Uterus after excision of rudimentary horn.

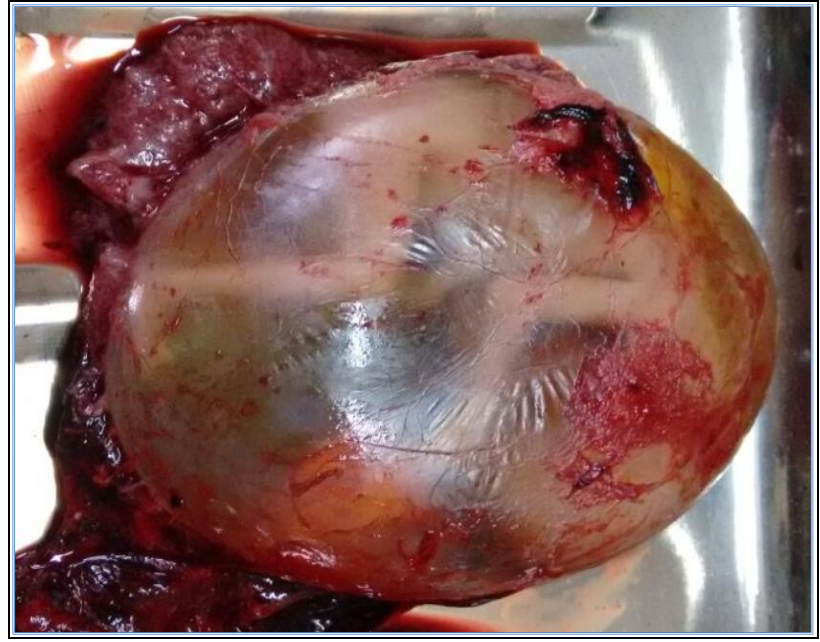

Figure 3: Fetus recovered en-sac from the peritoneal cavity.

\section{DISCUSSION}

Mullerian anomalies were first classified in 1979 by Buttram and Gibbons and further revised by the American Society of Reproductive Medicine in 1988. Unicornuate uterus is a type 2 classification with unilateral hypoplasia or agenesis that can be further subclassified into communicating, non-communicating, no cavity, and no horn. ${ }^{2}$ The incidence of uterine congenital anomalies because of Mullerian defects in the normal fertile population is $3.2 \%$. A unicornuate uterus accounts for $2.4 \%-13 \%$ of all Mullerian anomalies. ${ }^{3} 72-85 \%$ of the rudimentary horns are non-communicating with the cavity. Pregnancy in a rudimentary horn is rare and occurs most commonly in a non-communicating horn. The only possible explanation for pregnancy to occur in this case is by transperitoneal migration of spermatozoa through the contralateral tube. The incidence of RHP is estimated at 1 per 100,000 to 140,000 pregnancies. ${ }^{4}$ The natural history of RHP is usually rupture of the pregnant horn during the second or third trimester, resulting in lifethreatening heavy bleeding.

The first case of uterine rupture associated with rudimentary horn was reported in 1669 by Mauriceau. ${ }^{5}$ The timing of rupture varies from 5 to 35 weeks depending on the horn musculature and its ability to hypertrophy and dilate. ${ }^{6} 70-90 \%$ rupture before 20 weeks and can be catastrophic. As the uterine wall is thicker and more vascular, bleeding is more severe in rudimentary horn pregnancy rupture. ${ }^{7}$ Kadan and Romano described rudimentary horn rupture as the most significant threat to pregnancy and a life-threatening situation. Maternal mortality rate before 1900 was reported to be $47.6 \%{ }^{8}$ Rupture of the horn is still seen but no case of maternal death has been published since $1960 .^{9}$

Early diagnosis of mullerian anomalies is essential and can be challenging. Ultrasound, hysterosalpingogram, hysteroscopy, laparoscopy, and MRI are diagnostic tools. 
Fedele et al. have found ultrasonography to be useful in the diagnosis of pregnancy in rudimentary horn. ${ }^{10}$ But the sensitivity of ultrasound is only $26 \%$ and sensitivity decreases as the pregnancy advances. ${ }^{11}$ The differential diagnosis of sonographically suspected RHP is a tubal pregnancy, cornual pregnancy, and an intrauterine pregnancy in a bicornuate uterus. A tubal pregnancy will not show a ring of myometrium surrounding the gestational sac, but the differentiation between the 2 latter conditions and RHP may be difficult. Variation in thickness of the myometrium in 2 horns and a marked distance between them favor the diagnosis of a RHP. In contrast to RHP, continuity between the endometrium lining the gestational sac and the other uterine horn is typical for a pregnancy in a bicornuate uterus. ${ }^{12}$ Tsafrir et al. reported 2 cases of rudimentary horn pregnancy found in the first trimester by sonography and confirmed by MRI. They outlined a set of criteria for diagnosing pregnancy in the rudimentary horn. ${ }^{13}$ They are

1. A pseudo pattern of asymmetrical bicornuate uterus

2. Absent visual continuity tissue surrounding the gestation sac and the uterine cervix

3. Presence of myometrial tissue surrounding the gestational sac.

Use of labor induction agents for termination of pregnancy in a rudimentary horn is unsuccessful and can lead to rupture of the horn. Samuels and Awonuga reported rupture after use of misoprostol due to misdiagnosis. ${ }^{14} \mathrm{~A}$ similar case was reported by Kanagal and Hanumanalu. ${ }^{15}$

The traditional treatment of RHP is laparotomy and surgical removal of the pregnant horn to prevent rupture and recurrent RHP, as was done in our case. In recent years, several cases of RHP were treated by laparoscopy using various techniques. Dulemba et al reported removing the pregnancy contents using a vaginal cannula inserted through the posterior fornix. There are instances of early diagnosis and laparoscopic excision of rudimentary horns. ${ }^{16}$ Dicker et al. removed a small rudimentary horn through the suprapubic laparoscopic port. ${ }^{17}$ Yoo et al. resected a pregnant horn of $5 \times 5 \mathrm{~cm}$ laparoscopically. ${ }^{18}$ Yahata et al. used endoscopic stapler to transect a fibrous band connecting the rudimentary horn to the uterus. ${ }^{19}$ Medical management with methotrexate and its resection by laparoscopy is also reported. Edelman et al. showed a case detected at an early gestational week and treated successfully with methotrexate administration. However, the patient underwent surgery 6 months later to remove the rudimentary horn, which contained degenerative tissue. ${ }^{20}$

\section{CONCLUSIONS}

Despite advances in ultrasound and other diagnostic modalities, prenatal diagnosis remains elusive, with confirmatory diagnosis being laparotomy. The diagnosis can be missed in ultrasound especially in inexperienced hands. Precious time may be lost due to delay in diagnosis or misdiagnosis and the general condition of the person may worsen. Timely resuscitation, surgery, and blood transfusion are needed to save the patient. Proper diagnostic methods and early referral from the peripheral hospitals is needed to reduce the morbidity and mortality of the patients. There is a need for an increased awareness of this condition especially in developing countries where the possibility of detection before pregnancy or before the rupture is unlikely, and precious time is lost in shifting these women to the referral hospital.

\section{Funding: No funding sources \\ Conflict of interest: None declared \\ Ethical approval: Not required}

\section{REFERENCES}

1. Stovall TG, McCord ML. Early pregnancy loss and ectopic pregnancy. In: Berek JS, Adashi EY, Hillard PA, editors. Novak's Gynecology. 12th edition. Baltimore: William \& Wilkins; 1996. pp. 487-523.

2. Hassan CHC, Kadir A, Karim A, Ismail NAM, Omar $\mathrm{MH}$. Case report of ruptured non-communicating right rudimentary horn pregnancy: an acute emergency. Acta Medica. 2011;54(3):125-6.

3. Simon C, Martinez L, Pardo F, Tortajada M, Pellicer A. Mullerian defects in women with normal reproductive outcome. Fertility and Sterility. 1991;56(6):1192-3.

4. Sevtap HK, Aral AM, Sertac B. An early diagnosis and successful local medical treatment of a rudimentary uterine horn pregnancy: a case report. Archives of Gynecology and Obstetrics. 2007;275(4):297-8.

5. Mauriceau F. Traite des maladaies des femmes grosses. Vol. 1. Paris, France: Compaigne des libraries; 1721

6. O'leary JL, O'leary JA. Rudimentary horn pregnancy. Obstetrics and Gynecology. 1963;22:3714.

7. Chowdhury S, Chowdhury T, Azim E. Pregnancy in a non-communicating rudimentary horn of uterus: a clinical case report. Bangladesh Medical Journal. 2010;39(1):47-8.

8. Kadan Y, Romano S. Rudimentary horn pregnancy diagnosed by ultrasound and treated by laparoscopy a case report and review of the literature. Journal of Minimally Invasive Gynecology. 2008;15(5):527-30.

9. Nahum G. Rudimentary uterine horn pregnancy: the 20th-century worldwide experience of 588 cases.Journal of Reproductive Medicine. 2002;47(2):151-63.

10. Fedele L, Dorta M, Vercellini P, Brioschi D, Candiani GB. Ultrasound in the diagnosis of subclasses of unicornuate uterus. Obstetrics and Gynecology. 1988;71(2):274-7.

11. Jayasinghe Y, Rane A, Stalewski H, Grover S. The presentation and early diagnosis of the rudimentary 
uterine horn. Obstetrics and Gynecology. 2005;105(6):1456-67.

12. Kriplani A, Relan S, Mittal S, Buckshee K. Prerupture diagnosis and management of rudimentary horn pregnancy in the first trimester. Eur J Obstet Gynecol Reprod Biol 1995; 58:203-5.

13. Tsafrir A, Rojansky N, Sela HY, Gomori JM, Nadjari M. Rudimentary horn pregnancy: firsttrimester prerupture sonographic diagnosis and confirmation by magnetic resonance imaging. Journal of Ultrasound in Medicine. 2005;24(2):21923.

14. Samuels TA, Awonuga A. Second-trimester rudimentary uterine horn pregnancy: rupture after labor induction with misoprostol. Obstetrics and Gynecology. 2005;106(5):1160-2.

15. Deepa V. Kanagal and Lokeshchandra C. Hanumanalu. Ruptured Rudimentary Horn Pregnancy at 25 Weeks with Previous Vaginal Delivery: A Case Report. Case Rep Obstet Gynecol. 2012; 2012: 985076.

16. Dulemba JF, Midgett WA, Freeman MV. Laparoscopic management of a rudimentary horn pregnancy. J Am Assoc Gynecol Laparosc 1996;3:S10-1.

17. Dicker D, Nitke S, Shoenfeld A, Fish B, Meizner I, Ben-Rafael Z. Laparoscopic management of rudimentary horn pregnancy. Hum Reprod. 1998;13:2643-4.

18. Yoo EH, Chun SH, Woo BH. Laparoscopic resection of a rudimentary horn pregnancy. Acta Obstetricia et Gynecologica Scandinavica. 1999;78(2):167-8.

19. Yahata T, Kurabayashi T, Ueda H, Kodama S, Chihara T, Tanaka K. Laparoscopic management of rudimentary horn pregnancy: a case report. Journal of Reproductive Medicine for the Obstetrician and Gynecologist. 1998;43(3):223-6.

20. Edelman AB, Jensen JT, Lee DM, Nichols MD. Successful medical abortion of a pregnancy within a noncommunicating rudimentary uterine horn. Am J Obstet Gynecol. 2003;189:886-7.

Cite this article as: Goverdhan NA, Patankar A. Ruptured ectopic pregnancy in rudimentary horn. Int J Reprod Contracept Obstet Gynecol 2016;5:124750. 